\title{
Urinary epidermal growth factor as a marker for lupus nephritis: clinical, laboratory, and histopathological study
}

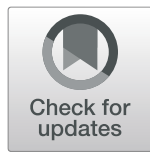

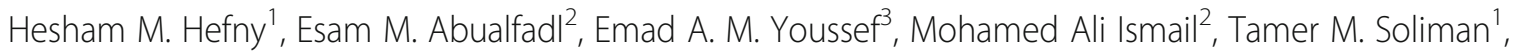
Ahmed Roshdi Hamed Ahmed ${ }^{4}$ and Hanan S. M. Abozaid ${ }^{2^{*}}$ (D)

\begin{abstract}
Background: Lupus nephritis can be seen in up to 60\% of all SLE patients with 10-15\% of nephritis patients progressing to end-stage renal disease; late diagnosis of lupus nephritis is correlated with a higher frequency of renal insufficiency. The study aim is determination of the value of urinary human epidermal growth factor (urinary EGF) as an early biomarker of lupus nephritis in SLE patients and its relevance to disease activity and renal histopathology.

Results: The study included 58 SLE patients and 30 healthy controls; a significant difference was noticed between SLE and controls in urinary protein, creatinine, protein/creatinine ratio, and urinary EGF. The mean level of urinary EGF was less in classes IV and V renal nephritis than in classes I, II, and III.

There is a significant difference in urinary EGF $(33 \pm 29,27 \pm 16, P=0.04)$ between class II and class III lupus nephritis, with no significant differences in urinary protein, creatinine, protein/creatinine ratio, and SLEDAI. On the other hand, the comparison between classes II and IV showed significant difference not only in urinary EGF $(33 \pm 29,11.7 \pm 4.9 \mathrm{~m}$, $P=0.003)$, but also in SLEDAI $(37.4 \pm 8,70.5 \pm 27, P=0.007)$, and protein/creatinine ratio $(0.98 \pm 0.62,3 \pm 1.8, P=0.006)$.

Conclusion: This study raises the attention to test the sensitivity of urinary EGF in detecting the early and the subsequent changes in renal pathology of SLE patients as an easy, non-invasive, accurate, cheap marker that could help in following up the nephritis progression and adjusting the plan of treatment; also, it can be used to guide the time of biopsy or as an alternative in cases where renal biopsy is contraindicated.
\end{abstract}

\section{Background}

One of the potentially life-threatening diseases is systemic lupus erythematosus (SLE). SLE owns a broad range of clinical manifestations with often unpredictable temporal sequence of organ involvement and disease flares that may cause permanent injury [1]. Lupus nephritis $(\mathrm{LN})$ can be seen in up to $60 \%$ of all SLE patients with $10-15 \%$ of nephritis patients progressing to endstage renal disease (ESRD) requiring hemodialysis [2].

\footnotetext{
* Correspondence: hanan72eg@yahoo.com

${ }^{2}$ Rheumatology and Rehabilitation Department, Sohag Faculty of Medicine, Sohag University, Sohag 82524, Egypt

Full list of author information is available at the end of the article
}

Late diagnosis of lupus nephritis is correlated with a higher frequency of renal insufficiency [3]. The increased incidence of ESRD underlines the importance of early diagnosis in this difficult to control disease with unpredictable course [4].

The ideal biomarker in SLE patients with suspicion or confirmation of LN should have the following properties: (1) be specific for renal involvement, (2) have a good correlation with kidney activity or damage, (3) be useful for serial monitoring, (4) be superior to conventional clinical or laboratory parameters, (5) possess the ability to assess the severity of renal involvement, (6) be costeffective, and (7) easy to perform and available in most clinical laboratories [1].

\section{Springer Open}

(c) The Author(s). 2021 Open Access This article is licensed under a Creative Commons Attribution 4.0 International License, which permits use, sharing, adaptation, distribution and reproduction in any medium or format, as long as you give appropriate credit to the original author(s) and the source, provide a link to the Creative Commons licence, and indicate if changes were made. The images or other third party material in this article are included in the article's Creative Commons licence, unless indicated otherwise in a credit line to the material. If material is not included in the article's Creative Commons licence and your intended use is not permitted by statutory regulation or exceeds the permitted use, you will need to obtain permission directly from the copyright holder. To view a copy of this licence, visit http://creativecommons.org/licenses/by/4.0/. 
In a longitudinal study by Moroni et al [5], antidsDNA, anti-C1q, C3, and C4 all had poor positive predictive values (ranging from 28 to 38\%). Although the best multivariate analysis model for renal flare prediction was obtained by combining anti-C1q with $\mathrm{C} 3$ and $\mathrm{C} 4$, their data clearly showed that anti-C1q antibodies were less reliable in predicting flares in non-proliferative nephritis and flares in the presence of anti-phospholipid antibodies. Furthermore, none of these traditional markers has been shown to possess the ability to predict histology. Clearly, the lack of specificity of our current markers for lupus nephritis and inability to predict histology highlight the pressing need for a true biomarker for lupus nephritis.

Abdou et al. [6] assessed the levels of urinary LXA4 in SLE patients and showed that the urinary LXA4/creatinine ratio levels were significantly lower in cardiovascular and neuropsychiatric manifestations and non-significantly lower in patients with nephritis.

Studies which demonstrated the potential use of urinary biomarkers of LN activity showed correlation with disease activity, renal flare, and histological damage and may help in monitoring the response to immunosuppressive treatment; however, studies about biomarkers in LN still involve relatively few cohorts. The urinary biomarkers are still not superior to renal biopsy, which remains the gold standard to determine LN activity and chronicity [7].

Human epidermal growth factor (urinary EGF), a 6000 molecular weight polypeptide, was first isolated by Cohen and Carpenter in 1975 [8]. EGF is a growth factor that stimulates cell growth, proliferation, and differentiation by binding to its receptor EGFR, some studies found that urinary EGF has a role in the development of body organs such as the brain, lungs, blood vessels, and kidneys [9].

Urinary EGF is locally produced in several tissues, such as Henle's loop and the distal convoluted tubule in the kidney, salivary glands, and duodenum [10]. In the kidney, urinary EGF is involved in the repairing process of renal tissues [11].

High concentrations of urinary EGF can be found in the urine. Based on in vitro experiments, it has been previously suggested that urinary EGF originates from the ultrafiltrate. However, in vivo, it was shown in rats and in humans that the urinary EGF is mainly produced in the kidney itself. Therefore, it is generally accepted that the urinary EGF excretion reflects the renal EGF production [11-13]. Reduced concentrations of urinary EGF in the urine have been previously observed in diabetes nephropathy, IgA nephropathy, adult polycystic kidney disease, and children with chronic renal failure $[14,15]$. Also, the possibility that urinary EGF might serve as a surrogate marker for functional regeneration of the renal tubules, reflecting their ability to respond to future acute or chronic injury, was recently put forward [16].

This study is conducted to determine the value of urinary human epidermal growth factor (urinary EGF) as an early biomarker of lupus nephritis in SLE patients and its relevance to disease activity and renal histopathology progression.

\section{Methods}

A cross-sectional observational study included 58 patients diagnosed with SLE, fulfilling the 2012 Systemic Lupus International Collaborating Clinics (SLICC) classification criteria of SLE [17], and have signs of renal involvement (hematuria, urinary cast, proteinuria, or histopathologic picture of nephritis); these patients have been admitted to the Department of Rheumatology and Rehabilitation that was during the period between $\mathrm{Au}$ gust 2017 and December 2019. The protocol of the study was approved by the local Ethics Committee with number IBR $\neq \mathrm{S} 20-135$ and conforms to the guidelines of the Declaration of Helsinki.

\section{Patient and public involvement}

The researchers explained the study protocol and aim of the work to all the participants, and patients' consent was signed.

Drug-induced lupus, discoid lupus without systemic manifestations, and diabetic patients were excluded. The following data were collected: full medical history; general examination; cardiovascular, chest, abdominal, neurological, and locomotor system examination; age at disease onset (defined at the time of onset of symptoms attributed to SLE); the duration of the disease (defined as the time from disease onset until the date of visit); the clinical features of SLE; routine laboratory; and autoimmune tests for each patient had been done.

For disease activity assessment, we used the SLEDAI index [18].

-Thirty healthy controls matched for age and sex were recruited from the officers in the hospital and volunteers.

\section{Laboratory renal investigations}

The patients and healthy volunteers were instructed to collect a spot midstream urine sample in a clean sterile container. For SLE patients, the sample was collected at the day of renal biopsy.

1. Spot urine protein/creatinine ratio $(\mathrm{u}-\mathrm{P} / \mathrm{C}$ ratio): both urinary protein and creatinine concentrations were measured by turbidimetric assay and kinetic colorimetric Jaffé method, respectively, using Cobas c311 Chemistry Analyzer System (Roche Diagnostics, GmbH, Mannheim, Germany). u-P/C 
ratio in spot urine samples was calculated by dividing the urinary protein concentration in $\mathrm{mg} / \mathrm{dL}$ by urine creatinine concentration in $\mathrm{mg} / \mathrm{dL}$. u-P/C ratio of less than $0.2 \mathrm{mg} / \mathrm{mg}$ was considered within normal limits, whereas a ratio in excess of 3.5 was considered as "nephrotic-range" proteinuria [19].

2. Detection of urinary human epidermal growth factor (EGF): after collection of urine sample in a sterile container, it was centrifuged at the speed of 2000-3000 rpm for $20 \mathrm{~min}$. Supernatant was removed; if precipitation appeared, the urine sample was centrifuged again. The supernatants were collected and were divided into aliquots and stored at $-80{ }^{\circ} \mathrm{C}$. Urinary EGF was measured in urine samples using an enzyme-linked immunosorbent assay (ELISA) kit (SinoGeneClon Biotech Co., Ltd, No.28 Cangxin Road, YuHang District 311112, HangZhou, China, CATALOG \#: SG-10583), according to the manufacturer's instructions. A standard curve was prepared by serial dilution of the standard supplied with the kit. Standards and diluted urine samples were added to a 96-well plate pre-coated with purified Human EGF antibody. The plate was incubated for $30 \mathrm{~min}$ at $37^{\circ} \mathrm{C}$. Following complete plate washing, combined EGF with HRP-labeled conjugate became antibody-antigen-enzyme-antibody complex. The detection antibody was incubated for $30 \mathrm{~min}$ at $37^{\circ} \mathrm{C}$, and after complete plate washing, tetramethylbenzidine (TMB) substrate was added and incubated for $15 \mathrm{~min}$ at $37^{\circ} \mathrm{C}$ with avoidance of light. TMB substrate became blue color as HRP enzyme catalyzed. The enzyme reaction was terminated by the addition of a stop solution with change of color from blue to yellow. The absorbance of the color change was measured at $450 \mathrm{~nm}$ using the Thermo Fisher Scientific Multiskan EX Microplate Reader (Thermo Fisher
Scientific Oy, FI-01621 Vantaa, Finland). The concentration of human EGF in samples was determined by comparing the O.D. of the samples to the standard curve.

\section{Statistical analysis}

Data was analyzed by SPSS version 20.0 statistical package; data were presented as number and percent, mean $\pm \mathrm{SD}$, or median and range as appropriate. Student's $t$ test and multivariate analysis were used for comparing means between different groups; Pearson correlation coefficient $(r)$ was used to test the association between quantitative variables. A $P$-value less than 0.05 was considered statistically significant.

\section{Results}

The patients' mean age is $47.2 \pm 14.6$ years, with 53 females (91.4\%), and the mean disease duration in years is $5.4 \pm 4.2$; SLEDAI mean \pm SD was $12.3 \pm 9.4$, with minimum of 2 and maximum of 22; medications were $100 \%$ hydroxychloroquine, 69\% mycophenolate mofetil, and $17.2 \%$ azathioprine and $86 \%$ corticosteroid; the main data of the patients is displayed in (Table 1).

The comparison between the patients and the control group was significant in urine protein, urine creatinine, protein/creatinine ratio, and in urine EGF level (Table 2).

We found no significant differences in urinary EGF level between speckled and homogenous ANA pattern and positive and negative anti-dsDNA.

The is no significant correlation of urinary EGF level with urinary $\mathrm{P} / \mathrm{C}$ ratio, or with any SLE disease parameters and renal laboratory tests except for ESR where there was a negative significant correlation $(r=-0.72, P=0.002)$.

With classification of renal biopsy according to the International Society of Nephrology/Renal Pathology Society 2003 classification of lupus nephritis [20], we noticed that the mean level of urinary EGF was less in classes IV and V than in classes I, II, and III

Table 1 The main demographic data for the patients

\begin{tabular}{|c|c|c|c|c|c|}
\hline Variable & Mean \pm SD & Variable & Percent (\%) & Variable & Percent (\%) \\
\hline Disease duration yr & $5.4 \pm 4.2$ & Females & 91.4 & ANA & 100 \\
\hline SLEDAI & $12.3 \pm 9.4$ & Alopecia & 45.5 & dsDNA & 60 \\
\hline WBC $\left(\times 10^{9} / 1\right)$ & $7.2 \pm 3.4$ & Malar rash & 54.5 & Speckled ANA & 60.5 \\
\hline $\operatorname{PLT}\left(\times 10^{9} / \mathrm{l}\right)$ & $272 \pm 135$ & Photosensitivity & 77.3 & Homogenous ANA & 33.5 \\
\hline $\mathrm{Hgb}(\mathrm{g} / \mathrm{dl})$ & $9.9 \pm 2.4$ & DLE rash & 31.8 & Others ANA patterns & 6 \\
\hline $\mathrm{u}-\mathrm{P} / \mathrm{C}(\mathrm{mg} / \mathrm{mg})$ & $1.2 \pm 1.2$ & Oral/nasal ulcers & 54.5 & Anti La & 25 \\
\hline $\mathrm{ESR}(\mathrm{mm})$ & $71 \pm 49.8$ & Pericarditis & 13.6 & Anti Ro & 45 \\
\hline C3 (mg/dl) & $62 \pm 35.4$ & Pleurisy & 9.6 & Ribosomal P0 & 20 \\
\hline $\mathrm{C} 4$ (mg/dl) & $23 \pm 12.6$ & Anti Sm & 10 & APL & 5.3 \\
\hline
\end{tabular}

WBC white blood cells, PLT platelet count, Hgb hemoglobin, ESR erythrocyte sedimentation rate, C3 complement 3, C4 complement 4, DLE discoid lupus, Both both speckled and homogenous ANA, APL anti-phospholipid Abs, $u-P / C$ urinary protein/creatinine ratio 
Table 2 Comparison between the patients and the controls

\begin{tabular}{llll}
\hline Variable & Patients (58) & Control (30) & $P$-value \\
\hline Age, year & $31.6 \pm 9.4$ & $32.5 \pm 6.4$ & 0.7 \\
Urine protein & $106.6 \pm 63.8$ & $5.7 \pm 0.95$ & 0.002 \\
Urine creatinine & $128.4 \pm 31.3$ & $136 \pm 145$ & 0.42 \\
Protein/creatinine & $1.02 \pm 0.57$ & $0.06 \pm 0.036$ & 0.03 \\
Urinary EGF & $30.2 \pm 16.7$ & $50.7 \pm 0.9$ & 0.001 \\
\hline
\end{tabular}

$P$ value less than 0.05 is significant

Urinary EGF urinary epidermal growth factor

(Table 3 and histopathological picture for sample of patients in Fig. 1).

Histological renal biopsy showed significant negative correlation with urinary EGF $(r=-0.55, P=0.008$, Fig. 2) and $\operatorname{ESR}(r=-0.56, P=0.03)$.

Due to the small number of patients in classes I and V nephritis, we started the comparison with class II.

By independent $T$ test between class II and class III lupus nephritis, there were no significant differences in urine protein, urine creatinine, protein/creatinine ratio, and SLEDAI, but there was significant differences in urinary EGF $(33 \pm 29,27 \pm 16, P=0.04)$, while comparison between classes II and IV showed significant differences in SLEDAI $(37.4 \pm 8,70.5 \pm 27, P=0.007)$, in protein/creatinine ratio $(0.98 \pm 0.62,3 \pm 1.8, P=0.006)$, and urinary EGF $(33 \pm 29,11.7 \pm 4.9 \mathrm{~m}, P=0.003)$.

We further tested the relation of renal biopsy with urinary EGF, protein/creatinine ratio, and SLEDAI through the linear regression analysis which showed only significance with the urinary EGF level (Table 4 and supplementary tables $(4 a-4 b-4 c)$ ).

ROC curve has been created to test urinary EGF level as a predictor of lupus nephritis and showed cutoff value at $<40.6$ (Fig. 3).

\section{Discussion}

Renal biopsy with histological study of kidney tissue is an esteemed tool for diagnostic classification and prognostication in lupus nephritis patients, but we cannot deny the accompanied significant morbidity with the procedure of renal biopsy that why it is not usually performed serially. Furthermore, with an essentially "blind"

Table 3 Histological classification of renal biopsy

\begin{tabular}{lll}
\hline & Percent $(\%)$ of patients & Urinary EGF (mean \pm SD) \\
\hline Class I & 3.4 & $32 \pm 17.8$ \\
Class II & 60.3 & $33 \pm 29$ \\
Class III & 22.4 & $27.3 \pm 16$ \\
Class IV & 10.3 & $11.7 \pm 4.9$ \\
Class V & 3.4 & $13.4 \pm 5.7$ \\
\hline
\end{tabular}

Measurement of the level of urinary epidermal growth factor in each class of histological lupus nephritis needle biopsy, there can be a question of how representative is the limited number of glomeruli usually obtained of kidney activity and chronicity [1].

We seriously need a noninvasive, easily obtainable, and accurate marker that can be followed serially in monitoring lupus patients. Pathologic studies provide limited information because patients are not biopsied frequently, and clinical measures provide limited information since they do not reflect intrarenal injury very well. In the previous studies, many laboratory markers have been used, which include serological determination of serum anti-double-stranded (ds)DNA antibodies and complement levels, and those can be helpful clinically, but the correlation between them and lupus renal disease is lacking. Sensitivity and specificity for active lupus nephritis among all SLE patients are different with different studies and tests used [5, 21, 22].

Our study included 58 SLE adult patients, 53 (91\%) of them are females, the mean disease duration in years is $5.4 \pm$ 4.2 , and the patients showed significant differences with the healthy control in the renal lab tests (urine protein-protein/ creatinine ratio and urinary EGF level) which matches with the results of many other studies $[11,13,18,23]$.

Interestingly, we did not find significant correlations between urinary EGF level and urinary $\mathrm{P} / \mathrm{C}$ ratio, despite that urinary protein is known to be generally a simple marker for detecting renal glomerular disease activity, and that could be explained by the earliest change in the level of urinary EGF than p/c ratio, similar observations were present in studies that tested the urinary chemokines' correlation with the $\mathrm{u}-\mathrm{P} / \mathrm{C}$ ratio $[24,25]$.

Other clinical parameters such as $\mathrm{u}-\mathrm{P} / \mathrm{C}$ ratio and urinary EGF level did not show any significant correlation with the SLE disease parameters and renal laboratory tests, but the ESR showed negative significant correlation $(r=-0.72, P=0.002)$.

In the study of Worawichawong et al. [25], they tested the combined use of urinary biomarkers with opposing actions such as EGF and MCP-1 (monocyte chemoattractant protein-1) to offer additional information compared to either cytokine alone. Previously, in the ratio of urinary biomarkers, they found that urinary EGF/ MCP-1 ratio is independently associated with tubulointerstitial severity in primary glomerulonephritis. However, they did not address the benefit of EGF/MCP-1 ratio over EGF alone at discriminating renal histological grade when the additional costs of the MCP-1 assay is considered. By contrast, neutrophil gelatinase-associated lipocalin (NGAL) appeared to be strongly associated with proteinuria, and less useful as a biomarker of tubulointerstitial disease severity compared to EGF. They recommended for further prospective studies to support and evaluate role of EGF or EGF/MCP-1 as candidate biomarkers to guide to therapy in various types of GN. 


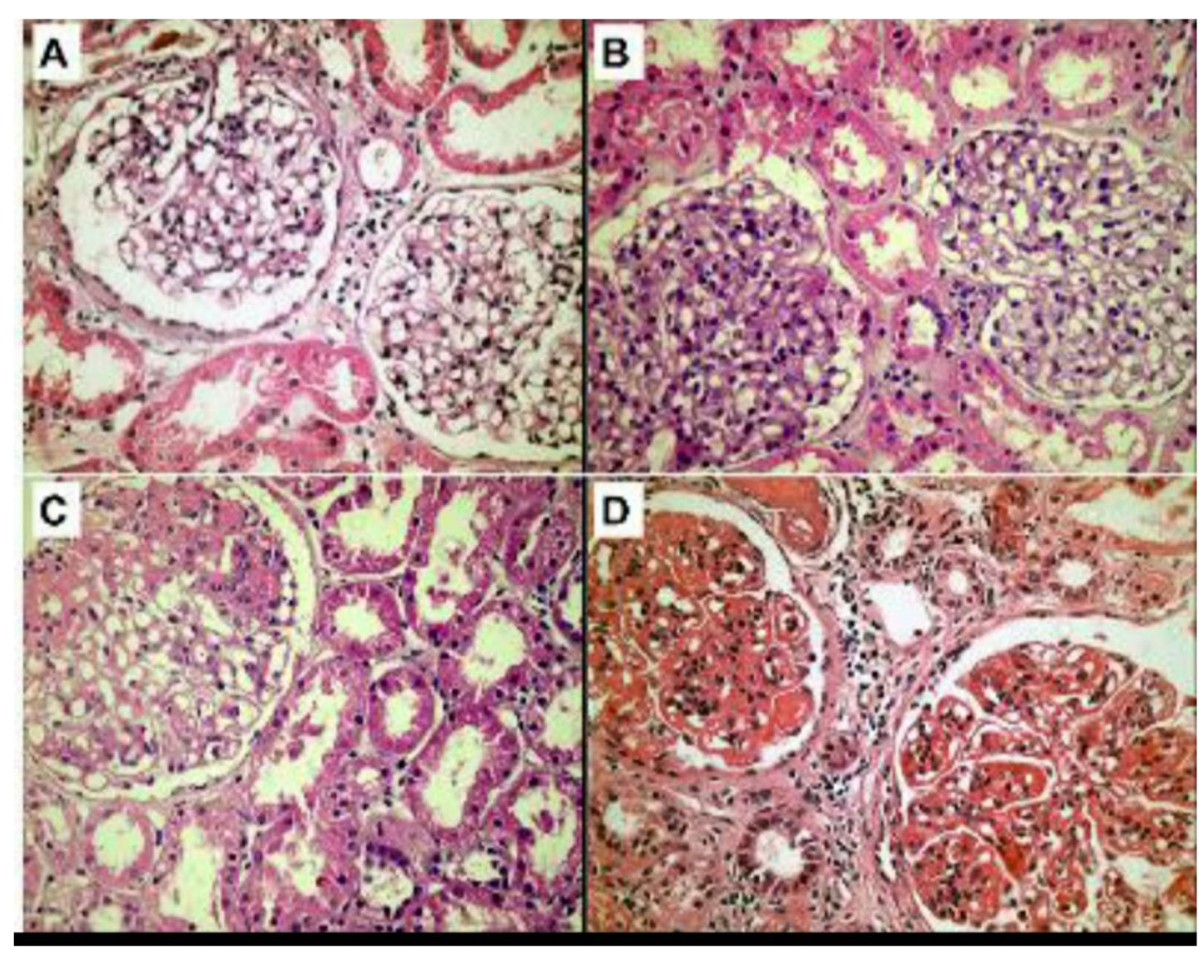

Fig. 1 Different stages of LN in investigated cases including a mesangial proliferative LN (stage II), b focal active/chronic LN (stage III A/C), c diffuse segmental LN (stage IV-S), and $\mathbf{d}$ diffuse global LN (IV-D). Hematoxylin and eosin stain; magnification is $\times 400$ for all

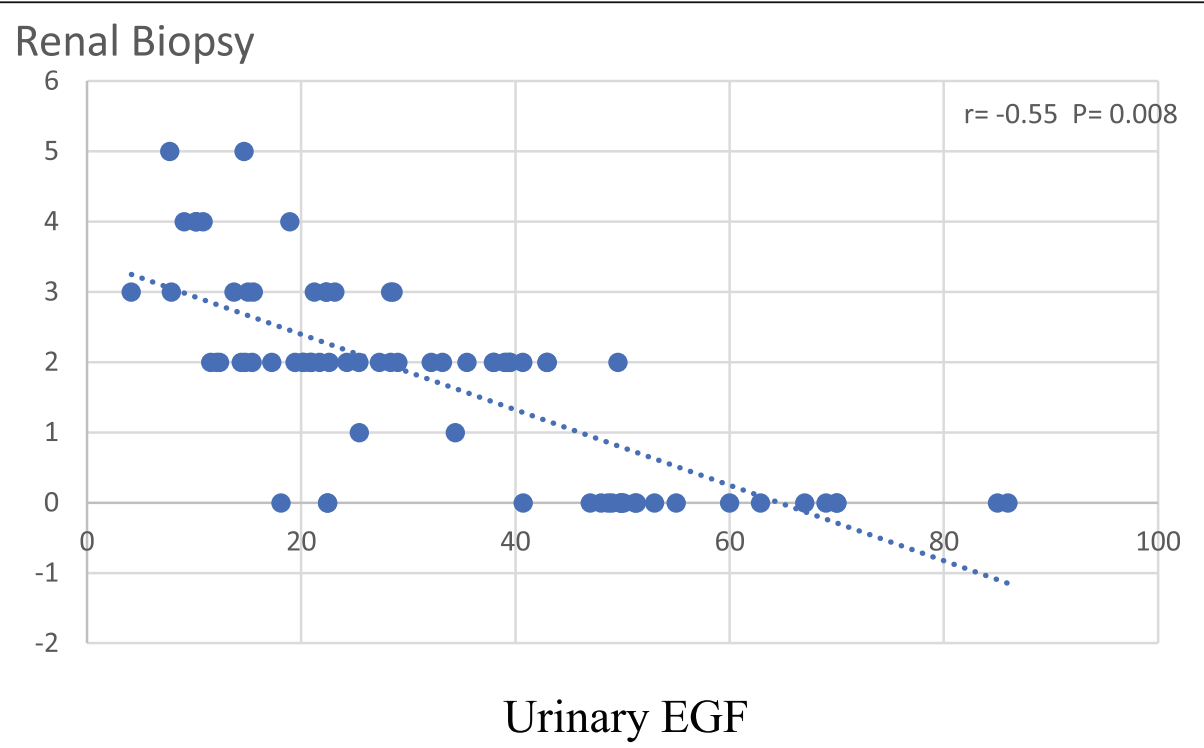

Negative significant correlation with $\mathrm{r}=-0.55$ and $\mathrm{P}=0.008$

Fig. 2 Correlation between the histological renal biopsy and urinary EGF. Negative significant correlation with $r=-0.55$ and $P=0.008$ 
Table 4 Linear regression for renal biopsy with each of urinary EGF, protein/creatinine ratio and SLEDAI

\begin{tabular}{llll}
\hline Linear regression & Urinary EGF & Protein/creatinine Ratio & SLEDAI \\
\hline Renal biopsy & Sig 0.036 & Sig 0.46 & Sig 0.98 \\
\hline
\end{tabular}

It was essential in this study to use the most approved tool for detecting the renal affection in SLE nephritis patients, it is the histological study of renal biopsy, and that work showed significant negative correlation with only urinary EGF level $(r=-0.55, P=0.008)$ and ESR $(r=$ - 0.56, $P=0.03$ ). This significant negative correlation with urinary EGF has been translated by the noticeable differences in its level among the renal histology classes, not only this, but it gave significant differences between two close classes (II and III), while widening the interclasses comparison (classes II and IV) the significant differences between the urinary EGF levels increased, and the other parameters appeared to give significant differences (SLEDAI, $\mathrm{u}-\mathrm{P} / \mathrm{C}$ ratio); this observation raise the attention to test the sensitivity of urinary EGF level for detecting the subsequent changes in renal pathology in SLE patients and soon, can be an excellent, noninvasive, accurate, cheap marker for following up the nephritis progression and adjusting the plan of treatment, and to support our finding, linear regression analysis of renal histological biopsy with the urinary EGF, protein/creatinine ratio, and SLEDAI was done and again has supported the urinary EGF importance by being significant only with it, and ROC curve has shown a cutoff value for urinary EGF $<40.6$ with a sensitivity $90.4 \%$ and specificity $83.3 \%$.

According to our knowledge this study is one of the few studies which tested the level of urinary EGF in adult systemic lupus nephritis and discussed its relationship with disease activity index and histological study in Arab SLE patients with determining cutoff value.

\section{Conclusion}

SLE renal biopsy histopathological results were parallel to the decrease in urinary EGF level. Urinary EGF is a simple urine test that showed significant reduction at the very early stage of lupus nephritis (class I) and showed a significant correlation as well with renal nephritis changes among classes.

Urinary EGF is a noninvasive, cheap, and easy way to follow the progression of lupus nephritis and could help in the early management and monitoring of progression.

The urinary EGF owns the advantage as a LN biomarker by having a good correlation with kidney activity

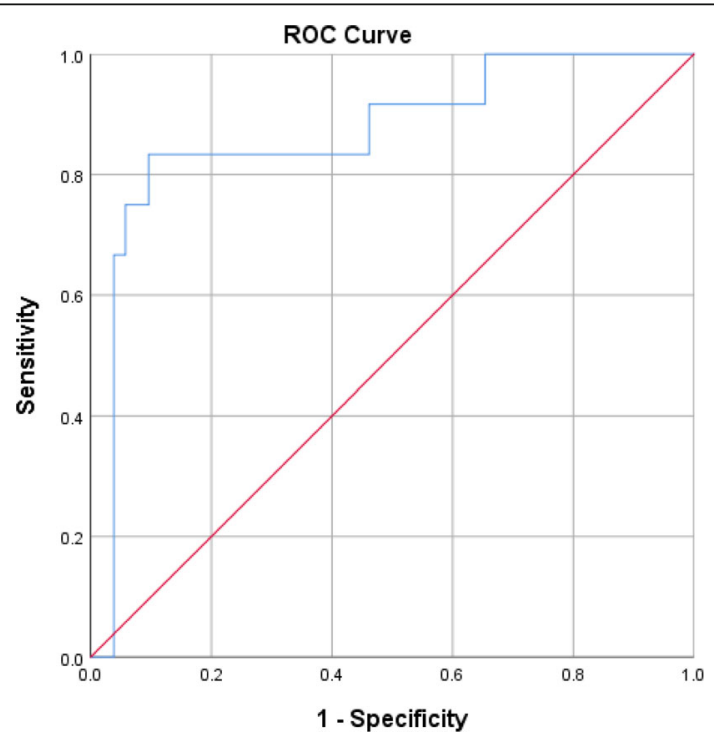

ROC curve analysis of urinary EGF as a predictor of Lupus Nephritis

\begin{tabular}{|l|l|l|l|l|l|l|l|}
\hline Variable & $\begin{array}{l}\text { Best } \\
\text { cut off } \\
\text { point }\end{array}$ & AUC (95 \% Cl) & $\begin{array}{l}\text { Sensitivity } \\
\text { (\%) }\end{array}$ & $\begin{array}{l}\text { Specificity } \\
\text { (\%) }\end{array}$ & $\begin{array}{l}\text { PPV } \\
\text { (\%) }\end{array}$ & $\begin{array}{l}\text { NPP } \\
\text { (\%) }\end{array}$ & P value \\
\hline Urinary EGF & $\leq 40.6$ & $\begin{array}{l}0.869 \\
(0.745: 0.992)\end{array}$ & 90.4 & 83.3 & 95.9 & 66.7 & $<0.0001$ \\
\hline
\end{tabular}

Fig. 3 ROC curve analysis of urinary EGF in relation with the histological renal biopsy 
and damage, being useful for serial monitoring, being superior to conventional clinical or laboratory parameters, possessing the ability to assess the severity of renal involvement, being cost-effective, and being easy to perform and available in most clinical laboratories

\section{Limitation of the study}

Our study is cross-sectional, while we recommend a future longitudinal study in order to provide more information and accuracy for its course and use as a biomarker for follow-up of SLE nephritis.

The study did not include SLE patients without nephritis as a comparative group, which is a step forward will be done in an extension study of this one.

\section{Supplementary Information}

The online version contains supplementary material available at https://doi. org/10.1186/s43166-021-00063-4.

Additional file 1. Supplementary Tables.

\section{Abbreviations \\ ANA: Antinuclear antibodies; APL: Anti-phospholipid; C3: Complement 3; C4: Complement 4; DLE: Discoid lupus; ds-DNA: Double strand DNA; ESRD: End-stage renal disease; EGFR: Epidermal growth factor receptor; ESR: Erythrocyte sedimentation rate; GN: Glomerulonephritis; LN: Lupus nephritis; SLE: Systemic lupus erythematosus; SLEDAI: Systemic Lupus Erythematosus Disease Activity Index; SLICC: Systemic Lupus International Collaborating Clinics; EGF: Epidermal growth factor; u-P/C ratio: Urine protein/creatinine ratio}

\section{Acknowledgements}

None

\section{Authors' contributions}

Esam M Abualfadl, Emad A.M. Youssef, and Mohamed Ali Ismail recruited the patients and did the clinical assessment and final approval of the draft. Hesham M Hefny and Tamer M Soliman managed the research protocol and did the laboratory work and final approval of the draft. Ahmed Roshdi Hamed Ahmed contributed to the pathological study of renal nephritis and final approval of the draft. Hanan S M Abozaid designed the protocol, recruited the patients, and contributed to data analysis, writing of the manuscript, and submitting it. The manuscript has been read and approved by all authors.

\section{Funding}

We confirm there is no governmental or institutional fund support.

\section{Availability of data and materials}

No additional data available

\section{Ethics approval and consent to participate}

The protocol of the study was approved by the local Ethics Committee with number IBR $\neq$ S20-135 and conforms to the guidelines of the Declaration of Helsinki

\section{Consent for publication}

Not applicable

\section{Competing interests}

The authors declare no competing interests.

\section{Author details}

${ }^{1}$ Clinical Pathology Department, Sohag Faculty of Medicine, Sohag University, Sohag, Egypt. ${ }^{2}$ Rheumatology and Rehabilitation Department, Sohag Faculty of Medicine, Sohag University, Sohag 82524, Egypt. ${ }^{3}$ Internal Medicine Department, Sohag Faculty of Medicine, Sohag University, Sohag, Egypt. ${ }^{4}$ Pathology Department, Sohag Faculty of Medicine, Sohag University, Sohag, Egypt.

Received: 18 November 2020 Accepted: 4 February 2021

Published online: 26 February 2021

\section{References}

1. Reyes-Thomas J, Blanco I, Putterman C (2011) Urinary biomarkers in lupus nephritis. Clin Rev Allergy Immunol 40:138-150

2. Weening JJ, D'Agati VD, Schwartz MM, Seshan SV, Alpers CE, Appel GB et al (2004) The classification of glomerulonephritis in systemic lupus erythematosus revisited. J Am Soc Nephrol 15(2):241-250

3. Esdaile JM, Joseph L, MacKenzie T, Kashgarian M, Hayslett JP (1994) The benefit of early treatment with immunosuppressive agents in lupus nephritis. J Rheumatol 21:2046-2051

4. Faurschou M, Starklint H, Halberg P, Jacobsen S (2006) Prognostic factors in lupus nephritis: diagnostic and therapeutic delay increases the risk of terminal renal failure. J Rheumatol 33:1563-1569

5. Moroni G, Radice A, Giammarresi G, Quaglini S, Gallelli B, Leoni A et al (2009) Are laboratory tests useful for monitoring the activity of lupus nephritis? A 6-year prospective study in a cohort of 228 patients with lupus nephritis. Ann Rheum Dis 68:234-237

6. Abdou MMS, Effat DA, Mansour LA, Abd El Baky NM, Salam MMA (2015) Urinary lipoxin A4 as a biomarker for systemic lupus erythematosus. Egypt Rheumatol Rehabil 42(2):55-61

7. Gasparin AA, Pamplona Bueno de Andrade N, Hax V, Tres GL, Veronese FV, Monticielo (2019) Urinary biomarkers for lupus nephritis: the role of the vascular cell adhesion molecule-1. Lupus 28(3):265-272

8. Cohen S, Carpenter G (1975) Human epidermal growth factor: isolation and chemical and biological properties. Proc Natl Acad Sci 72:1317-1321

9. Betsholtz C (2004) Insight into the physiological functions of PDGF through genetic studies in mice. Cytokine Growth Factor Rev 15:215-228

10. Zeng F, Harris RC (2014) Epidermal growth factor, from gene organization to bedside. Semin Cell Dev Biol 22:2-11

11. Chou JS, Reiser IW, Porush JG (1997) Aging and urinary excretion of epidermal growth factor. Ann Clin Lab Sci 27:116-122

12. Li Z, Zhao Z, Liu X, Su Z, Shang X, Wen J (2012) Prediction of the outcome of antenatal hydronephrosis: significance of urinary EGF. Pediatr Nephrol 27: 2251-2259

13. Grandaliano G, Gesualdo L, Bartoli F, Ranieri E, Monno R, Leggio A et al (2000) MCP-1 and EGF renal expression and urine excretion in human congenital obstructive nephropathy. Kidney Int 58:182-192

14. Dincer, Y., C. Akkaya, and S.J.U.N.O.A.J. (2018) Alagöz, Assessment of urinary epidermal growth factor level in patients with chronic kidney disease. Urol Nephrol Open Access J. 6:131-134.

15. Meybosch S, De Monie A, Anné C, Bruyndonckx L, Jürgens A, De Winter BY et al (2019) Epidermal growth factor and its influencing variables in healthy children and adults. PloS one 14:e0211212

16. Ju W, Nair V, Smith S, Zhu L, Shedden K, Song PX et al (2015) Tissue transcriptome-driven identification of epidermal growth factor as a chronic kidney disease biomarker. Sci Transl Med 7:316ra193

17. Petri M, Orbai AM, Alarcón GS, Gordon C, Merrill JT, Fortin PR et al (2012) Derivation and validation of the Systemic Lupus International Collaborating Clinics classification criteria for systemic lupus erythematosus. Arthritis Rheum 64:2677-2686

18. Gladman DD, Ibanez D, Urowitz MB (2002) Systemic lupus erythematosus disease activity index 2000. J Rheumatol 29:288-291

19. Ginsberg JM, Chang BS, Matarese RA, Garella S (1983) Use of single voided urine samples to estimate quantitative proteinuria. N Engl J Med 309:15431546

20. Park MH (2006) International Society of Nephrology/Renal Pathology Society 2003 Classification of Lupus Nephritis. Korean J Pathol 40:165-175

21. Oelzner P, Deliyska B, Fünfstück R, Hein G, Herrmann D, Stein G (2003) Anti$\mathrm{C1q}$ antibodies and antiendothelial cell antibodies in systemic lupus erythematosus-relationship with disease activity and renal involvement. Clin Rheumatol 22:271-278

22. Abd Elazeem Ml, Mohammed RA, Abdallah NH (2018) Correlation of serum interleukin-10 level with disease activity and severity in systemic lupus erythematosus. Egypt Rheumatol Rehabil 45(1):25 
23. Birmingham DJ, Merchant M, Waikar SS, Nagaraja H, Klein JB, Rovin BH (2017) Biomarkers of lupus nephritis histology and flare: deciphering the relevant amidst the noise. Nephrol Dial Transplant 32(suppl_1):i71-i79

24. Stangou M, Alexopoulos E, Papagianni A, Pantzaki A, Bantis C, Dovas S et al (2009) Urinary levels of epidermal growth factor, interleukin-6 and monocyte chemoattractant protein-1 may act as predictor markers of renal function outcome in immunoglobulin A nephropathy. Nephrol 14:613-620

25. Worawichawong S, Worawichawong S, Radinahamed P, Muntham D,

Sathirapongsasuti N, Nongnuch A (2016) Urine epidermal growth factor, monocyte chemoattractant protein-1 or their ratio as biomarkers for interstitial fibrosis and tubular atrophy in primary glomerulonephritis. Kidney Blood Press Res 41:997-1007

\section{Publisher's Note}

Springer Nature remains neutral with regard to jurisdictional claims in published maps and institutional affiliations.

\section{Submit your manuscript to a SpringerOpen ${ }^{\circ}$ journal and benefit from:}

- Convenient online submission

- Rigorous peer review

- Open access: articles freely available online

- High visibility within the field

- Retaining the copyright to your article

Submit your next manuscript at $\boldsymbol{\nabla}$ springeropen.com 